\title{
Oral medicine 4. Klinische aspecten, gevolgen en behandeling van smaak- en reukstoornissen
}

Er bestaat een nauwe samenhang tussen de reuk- en smaakperceptie. Veel chemosensorische stoornissen die leiden tot een gestoorde smaak zijn in feite reukstoornissen. Aandacht vragende oorzaken van chemosensorische stoornissen zijn veroudering, het gebruik van medicamenten, natuurlijke eiwitten, het mondbrandsyndroom, nervustrauma's, beluchtingsproblemen ter hoogte van het reukzintuig, beschadiging van het reukepitheel en oncologische aandoeningen of de behandeling daarvan. Een chemosensorische stoornis heeft gevolgen voor het genot van voedingsmiddelen en het psychisch welbevinden, kan leiden tot gewichtsverlies of gewichtstoename en tot te weinig inname van vitaminen en mineralen. De behandeling van een chemosensorische stoornis kan bestaan uit medicatie, een chirurgische correctie, verbetering van de mondgezondheid, reukrevalidatie en voedingsadviezen.

Vissink A, Jager-Wittenaar H, Visser A, Spijkervet FKL, Weissenbruch R van, Nieuw Amerongen A van. Oral medicine 4. Klinische aspecten, gevolgen en behandeling van smaak- en reukstoornissen

Ned Tijdschr Tandheelkd 2013; 120: 155-162

doi: $10.5177 /$ ntvt.2013.03.12138

\section{Inleiding}

Smaakperceptie en genot van voedingsmiddelen zijn onderhevig aan een scala van individuele en culturele factoren. Voor een goede smaak is een ongestoorde reuk van belang en daarom een essentiële zintuiglijke functie.

Het eerste van de 3 artikelen over reuk- en smaakstoornissen in de serie over oral medicine ging over de anatomie en de fysiologie die aan de reuk- en smaakperceptie ten grondslag liggen (Vissink et al, 2012). In dit artikel wordt ingegaan op een aantal klinische aspecten en gevolgen van de smaak- en reukperceptie en op een aantal therapeutische mogelijkheden bij stoornissen in de smaak- en reukperceptie.

\section{Klinische aspecten}

Voor chemosensorische stoornissen van smaak en reuk bestaat een gedifferentieerde terminologie (tab. 1). Hierbij moet men bedenken dat veel chemosensorische stoornissen die leiden tot een gestoorde smaak feitelijk reukstoornissen zijn (Vissink et al, 2012). Absolute smaakstoornissen komen minder vaak voor vanwege het grote aantal, de gespreide lokalisatie en de uitgebreide innervatie van de smaakreceptoren. Verlies van een aantal smaakreceptoren kan worden gecompenseerd door andere receptoren. Bovendien hebben de smaakcellen een hoge vervangingssnelheid ('turnover') van ongeveer 10 dagen. Men heeft berekend dat elke smaakreceptorcel slechts gedurende enkele uren wordt blootgesteld aan stimuli. Met andere woorden: de smaakreceptorcellen die worden gebruikt tij- dens het ontbijt, kunnen verschillen van de receptorcellen die actief zijn tijdens de lunch. De hoge vervangingssnelheid zorgt ervoor dat beschadiging van smaakreceptorcellen door chemische, thermische of mechanische stimuli gewoonlijk niet leidt tot een permanent verminderde potentie om schadelijke of vanwege voedingsoogpunt belangrijke stoffen waar te nemen (Spielman, 1998).

De reukperceptie wordt daarentegen verzorgd door 1 enkele, korte hersenzenuw, de nervus olfactorius. De vervangingssnelheid van de reukreceptorcellen is veel langzamer dan die van smaakreceptoren en duurt wel 4 tot 8 weken. Daardoor duurt het herstel van beschadigingen ook langer (Spielman, 1998). Mede als gevolg daarvan neemt boven de leeftijd van ongeveer 65 jaar vooral de reukperceptie af, terwijl het leeftijdseffect op de smaakperceptie relatief gering is (Ship en Weiffenbach, 1993; Ship, 1999).

Vrij algemeen wordt aangenomen dat de smaakperceptie bij ouderen is verminderd, vooral voor de perceptie van zout en bitter en in mindere mate van zoet. Dit is niet altijd het gevolg van het ouder worden, maar wordt vooral beïnvloed door medicatie. Wanneer meer dan 3 soorten medicamenten worden gebruikt, is de smaakdrempel voor zout 12 maal hoger, voor bitter 7 maal, voor umami 5 maal,

\begin{tabular}{|c|c|}
\hline \multicolumn{2}{|l|}{ Smaak } \\
\hline Ageusie & Onvermogen tot smaakperceptie \\
\hline Hemiageusie & Halfzijdig verlies van smaakperceptie \\
\hline Hypogeusie & Verminderd vermogen tot smaakperceptie \\
\hline Hypergeusie & Toegenomen vermogen tot smaakperceptie \\
\hline Dysgeusie & Veranderde smaakperceptie \\
\hline Parageusie & Kwalitatief veranderde smaakperceptie \\
\hline Smaakagnosie & $\begin{array}{l}\text { Onmogelijkheid tot juiste identificatie en classificatie } \\
\text { van smaakprikkels }\end{array}$ \\
\hline \multicolumn{2}{|l|}{ Reuk } \\
\hline Anosmie & Onvermogen tot reukperceptie \\
\hline Hyposmie & Verminderd vermogen tot reukperceptie \\
\hline Hyperosmie & Toegenomen vermogen tot reukperceptie \\
\hline Dysosmie & Veranderde reukperceptie \\
\hline Parosmie & Kwalitatief veranderde reukperceptie \\
\hline Reukagnosie & $\begin{array}{l}\text { Onmogelijkheid tot juiste identificatie en classificatie } \\
\text { van reukprikkels }\end{array}$ \\
\hline Kakosmie & $\begin{array}{l}\text { Perceptie van een geur die niet of in een andere vorm } \\
\text { aanwezig is }\end{array}$ \\
\hline Pseudosmie & $\begin{array}{l}\text { Inbeelding van geuren bij heftige emoties (olfactoire } \\
\text { illusie) }\end{array}$ \\
\hline Fantosmie & Olfactoire hallucinatie \\
\hline
\end{tabular}

Tabel 1. Terminologie van chemosensorische stoornissen (Mott en Leopold, 1991; Spielman, 1998). 


\section{Lokale aandoening}

Adenoïdhypertrofie

Carcinoom glandula submandibularis

Glossitis

Infectie of tumor glandula parotidea

Polyposis/rhinitis/sinusitis

Syndroom van Sjögren

Hyposialie

Infectie

Herpes simplex

HIV

Infectie van de bovenste luchtwegen

Neurologische aandoeningen

Cerebrovasculair accident

Cerebrovasculaire dementie

(kunnen perceptie en

beleving niet weergeven)

Migraine

Trauma capitis

Ziekte van Alzheimer

Ziekte van Parkinson

Multipele sclerose

Psychiatrische aandoeningen

Boulimie

Schizofrenie

Endocriene/metabole aandoeningen

Bijnierinsufficiëntie

Diabetes mellitus

Hypothyreoïdie

Maligniteit

Gastro-intestinale en leverziekten

Acute hepatitis

Chronische leverziekte

Levercirrose

\section{Iatrogene oorzaak}

Beschadiging van de chorda tympani

Radiotherapie

Tonsillectomie

Aangeboren aandoeningen

Palatoschisis
Hemiageusie

Dysgeusie

Dysgeusie voor zoet

Hypogeusie/ageusie

Toegenomen drempelwaarde

Smaakverlies

Hypogeusie/dysgeusie/parageusie

Gustatoire hallucinatie

Verstoorde smaakbeleving:

toegenomen drempelwaarde;

afgenomen identificatie

Subjectieve hypergeusie

Hypogeusie/ageusie/dysgeusie

Relapsfase, voorbijgaand

Hypogeusie voor zuur en bitter

Toegenomen drempelwaarde

Toegenomen identificatie en drempelwaarde

Hypogeusie/dysgeusie

Toegenomen drempelwaarde/dysgeusie

Toegenomen drempelwaarde

Toegenomen drempelwaarde

Hypogeusie/dysgeusie/ageusie

Toegenomen drempelwaarde

Focale ageusie/dysgeusie voor zout
Afgenomen drempelwaarde

Toegenomen drempelwaarde

Hyposmei/anosmie/parosmie

Toegenomen drempelwaarde

Anosmie

Afgenomen geuridentificatie

Afgenomen drempelwaarde; afgenomen drempelwaarde voor sucrose

Subjectieve hyperosmie

Hyposmie/anosmie/parosmie

Afgenomen identificactie; toegenomen drempelwaarde

Afgenomen identificactie; toegenomen drempelwaarde Voorbijgaand

Olfactorische hallucinaties

Afgenomen identificatie; toegenomen drempelwaarde Hyposmie/parosmie; afgenomen identificatie Dysosmie

Hyposmie

Hyposmie

Hyposmie/anosmie/parosmie; toegenomen drempelwaarde

Tabel 2. Oorzaken van systemische en lokale condities die zijn geassocieerd met chemosensorische stoornissen (Mott en Leopold, 1991; Spielman, 1998; Comeau et al, 2001; Van Nieuw Amerongen et al, 2008; Battaglia, 2011). 


\section{Casus 1}

Een vitale 80-jarige vrouw klaagde over smaakveranderingen. Zij bleek al maanden 2 maal daags de pijlers van een transmandibulair implantaat te reinigen met een $0,2 \%$ chloorhexidinegel vanwege peri-implantitis. De behandeling werd omgezet in het 1 maal daags gedurende 5 minuten lokaal appliceren van een $0,12 \%$ chloorhexidinegel en het vervolgens schoonspoelen van de gebitsprothese met water. Binnen een aantal weken had zij haar normale smaak terug.

\section{Casus 2}

Een 56-jarige vrouw die werd behandeld voor hypertensie klaagde over een droge mond en een bittere smaak. De klachten ontstonden kort nadat zij was gestart met het gebruik van een combinatiepreparaat voor de behandeling van hypertensie. Dit preparaat bevatte $50 \mathrm{mg}$ captopril en $25 \mathrm{mg}$ hydrochloorthiazide. De combinatie van de droge mond en de bittere smaak, waarbij de bittere smaak overheerste en progressief was, leidde ertoe dat zij in 8 maanden 30 kilogram afviel (van 90 naar 60 kilogram). Nadat het antihypertensivum captopril was vervangen door een ander medicament was de bittere smaak binnen een paar dagen verdwenen en was haar lichaamsgewicht na enkele weken met 7 kilogram toegenomen (Mauersberger en Witte, 1985)

voor zuren 4 maal en voor zoet 3 maal (Ritchie, 2002). Gebitsprothesen die het palatum bedekken kunnen ook de smaakdrempel verhogen, in het bijzonder voor zoet.

Tabel 2 geeft een overzicht van een groot aantal smaaken reukstoornissen waarbij de klacht over een smaakstoornis feitelijk vaak een reukstoornis betreft of een combinatie van een smaak- en een reukstoornis. Daarnaast treedt bij patiënten met dementie en/of neurogeneratieve degeneratie, dus ook op jonge leeftijd, vaak verlies van smaak en andere zintuiglijke perceptie op (Reuber et al, 2001; Battaglia, 2011; Dahlslett et al, 2012). Van belang is tijdelijke verstoringen van de smaak en/of reuk te onderscheiden van permanente veranderingen. Voorbeelden van een tijdelijke verstoring zijn de smaakveranderingen die optreden na gebruik van tandpasta en chloorhexidine (casus 1) (Van Nieuw Amerongen et al, 2008). Deze effecten worden vooral veroorzaakt door de detergentia (schuimmiddelen) zoals natriumlaurylsulfaat, die aan deze middelen zijn toegevoegd. Door menthol, dat vaak is toegevoegd, wordt de perceptie van zout, bitter en zuur verstoord. Langdurig gebruik van chloorhexidine zou een beschadiging van de celwanden van de smaakreceptorcellen veroorzaken (Helms et al, 1995; Van Nieuw Amerongen et al, 2008). Bij een lage dosering is dit effect reversibel.

Behalve de in tabel 2 genoemde oorzaken voor een verstoorde smaak- en/of reukperceptie vormt medicamentgebruik een belangrijke bron van chemosensorische stoornissen (casus 2) (Vissink et al,1999; Swart et al, 2001). Deze smaakveranderingen verdwijnen vaak na het staken van de medicatie. Meestal betreft het zogenoemde gedissocieerde veranderingen van smaak, waarbij vooral de veranderde perceptie van zoet optreedt. Vooral medicamenten die sulfhydrylgroepen bevatten, kunnen de smaakfunctie verstoren. Deze functionele groep is onder meer in staat een reactie aan te gaan met de restgroep van het aminozuur cysteïne. Mogelijk kunnen deze medicamenten de smaakeiwitreceptoren blokkeren. Ook niet-medicamenteuze sulfhydrylreagentia reduceren de zoetsmaak. Een overzicht van medicamenten die smaakveranderingen of smaakverlies kunnen veroorzaken, is weergegeven in tabel 3.

Smaakveranderingen kunnen behalve door geneesmiddelen ook worden veroorzaakt door natuurlijke verbindingen zoals het eiwit miraculine en gymneminezuur. Miraculine is een glycoproteïne afkomstig uit bessen van de West-Afrikaanse heester Synsepalum dulcificum, ook wel wonderfruit genoemd. Na consumptie van deze bessen worden zure voedingsmiddelen als zoet geproefd. Het mechanisme van deze smaakverandering is niet bekend. Gymneminezuur uit de bladeren van Gymnema sylvestre onderdrukt juist de zoete smaak.

Patiënten met het mondbrandsyndroom die tevens monddroogheid ervaren, klagen vaak over smaakstoornissen. De helft tot twee derde van deze patiënten klaagt over smaakveranderingen (Spielman, 1998). Zij hebben vooral een hogere drempel voor de zoetstimulus, terwijl de drempel voor bitter is verlaagd (Van Nieuw Amerongen et al, 2008). Ook is de identificatie van natriumchloride als zout en citroenzuur als zuur moeilijk voor vrouwen met het mondbrandsyndroom.

Iatrogene oorzaken van smaakstoornissen zijn beschadiging van de nervus lingualis, de chorda tympani, de nervus facialis en de nervus glossopharyngeus als complicatie van een chirurgische behandeling. Ook patiënten die radiotherapie in het hoofd-halsgebied hebben ondergaan, klagen vaak over smaakverlies en smaakverandering (casus 3). Door de radiotherapie treedt een veelal reversibele beschadiging van de smaakknoppen op, waarbij vanaf een cumulatieve bestralingsdosis van 15-30 Gy op de tong een verhoging van de smaakdrempels merkbaar wordt en vanaf een cumulatieve bestralingsdosis van 60 Gy een totaal smaakverlies kan optreden (Ripamonti et al, 1998; Hovan et al, 2010). Bij patiënten die radiotherapie ondergaan in het hoofd-halsgebied, raken de smaakkwaliteiten bitter en zout het vroegst en het sterkst beschadigd en de perceptie van zoet het minst (Ruo Redda en Allis, 2006). Door de grote regeneratiepotentie van de smaakknoppen wordt gewoonlijk een geleidelijk herstel van de smaakperceptie waargenomen in de maanden na het beëindigen van de radiotherapie. Wel blijkt dat vaak een blijvende smaakverandering is opgetreden (Ruo Redda en Allis, 2006). Deze smaakverandering kenmerkt zich vooral door het anders smaken van diverse voedingsmiddelen dan de patiënt zich kan herinneren van voor de radiotherapie. Door de smaakverandering gaan veel voedingsmiddelen vies smaken en ontstaat een aversie tegen eten met vaak gewichtsverlies als gevolg.

Van hemodialysepatiënten met ernstige nierfunctiestoornis is bekend dat zij, al of niet geïnduceerd door medicamenten, xerostomie en een verminderde smaakfunctie 
- $\quad$ Antiaritmica, zoals flecaïnide, propafenon

Antibiotica, zoals cefalosporinen (cefamandol, cefpirom), chinolonen (ciprofloxacine, norfloxacine), rifabutine

Antihypertensiva, zoals 'angiotensine converting enzyme'-remmers, amiloride, diltiazem, hydrochloorthiazide, nifedipine, propranolol, spironolacton

Antimycotica, zoals amfotericine B, griseofulvine, itraconazol, terbinafine

Antiprotozoïca, zoals metronidazol, pentamidine

Antireumatica, zoals fenylbutazon, penicillamine

Niet-steroïdale anti-inflammatoire medicamenten (NSAID), zoals ibuprofen, naproxen, piroxicam

Hypnotica, zoals flurazepam, triazolam, zopiclon

Oncolytica, zoals bleomycine, cisplatine, 5-fluorouracil, methotrexaat

Orale bloedglucoseverlagende middelen, zoals glipizide, metformine

Protonpompremmers, zoals lansoprazol, omeprazol

Diverse andere medicamenten, zoals acetazolamide, allopurinol, beclometason, carbamazepine, carbimazol, chloorhexidine, ciclosporine, clofibraat, dipyridamol, etidroninezuur, glycopyrronium, levodopa, lithiumzouten, morfine, nedocromil, nitroglycerine, paroxetine, procaïne, sibutramine, sumatriptan

Tabel 3. Medicamenten die smaakveranderingen of smaakverlies kunnen veroorzaken (Swart et al, 2001)

hebben. Deze bijwerkingen kunnen worden veroorzaakt door veranderingen in de concentratie van spoorelementen, onder andere zink. Toevoeging van zink aan de dialysevloeistof geeft verbetering van de smaakperceptie (Matson et al, 2003).

Beluchtingsproblemen ter hoogte van het reukzintuig in de bovenste neusgang kunnen leiden tot een gestoorde reuk (geleidingsanosmie). Een structurele afwijking in de neus, zoals een septumdeviatie en poliepen, leidt echter niet automatisch tot een verstoorde beluchting van deze regio en daardoor tot een reukstoornis. Daarentegen kunnen geringe, alleen endoscopisch waarneembare zwellingen van het slijmvlies in de neus wel leiden tot een verstoorde beluchting (Hüttenbrink, 1995). Tijdens chirurgische behandelingen van de neus, zoals in- en uitwendige correcties en behandelingen van de sinus maxillaris, en door neustrauma's kan het reukepitheel op korte en lange termijn beschadigd raken. Stompe hoofdtrauma's kunnen gepaard gaan met rupturen van de fila olfactoria nabij de lamina cribrosa en dat kan aanleiding geven tot een permanente anosmie of dysosmie.

Reukvermindering als gevolg van een directe beschadiging van het reukepitheel, perceptieanosmie, wordt onder andere gezien bij bacteriële en virale infecties, de inwerking van toxische stoffen en roken. Hoe meer iemand rookt, hoe sterker het reukvermogen afneemt (Hüttenbrink, 1995). Het gebruik van snuif- en pruimtabak bleek zelfs te kunnen leiden tot een smaakverstoring die tot 12 uur na gebruik kan aanhouden (Ackerman en Kasbekar, 1997). De smaakperceptie wordt door roken minder aangetast, hoewel bij zware rokers wel veranderingen in de morfologie van de papillae fungiformes en filiformes zijn waargenomen (Konstantinidis et al, 2010).

Ten slotte kunnen oncologische aandoeningen en de behandeling daarvan leiden tot ernstige smaak- en/of reukstoornissen. Veranderingen in smaak en reuk bij patiënten met een oncologische aandoening kunnen deel uitmaken van het cachexiesyndroom. Dit is een complex metaboolsyndroom dat niet alleen wordt gekenmerkt door gewichtsverlies en verminderde eetlust, maar ook door smaakveranderingen (Tan en Fearon, 2008). Bij alle soorten kanker kunnen veranderingen in de smaak en reuk optreden, hoewel deze bij patiënten met kanker in het hoofd-halsgebied vaker voorkomen dan bijvoorbeeld bij patiënten met borst- of longkanker (Hong et al, 2009).

\section{Gevolgen}

Een chemosensorische stoornis heeft directe gevolgen voor het genot van voedingsmiddelen en het psychisch welbevinden. Bij patiënten met een smaakstoornis kunnen bepaalde voedingsmiddelen te zoet, te zout, te zuur, te bitter of juist heel erg vies smaken (dysgeusie). Soms kunnen voedingsmiddelen zelfs helemaal niet meer worden geproefd (ageusie). Smaak- en/of reukvermindering (hypogeusie respectievelijk hyposmie), smaak- en/ of reukverandering (dysgeusie respectievelijk dysosmie) of smaak- en/of reukverlies (ageusie respectievelijk anosmie) kunnen leiden tot een verminderde eetlust en een verminderde voedselinname (casus 3) (Mattes et al, 1990; Mattes en Cowart, 1994). Patiënten met dysgeusie hebben een grote kans op een verminderde energie-inname (MattesKulig en Henkin, 1985). De verminderde energie-inname kan resulteren in gewichtsverlies en ondervoeding. Vooral bij patiënten met een smaak- en/of reukstoornis als gevolg

\section{Casus 3}

Een 62-jarige vrouw met een plaveiselcelcarcinoom van de tong werd chirurgisch behandeld en kreeg aanvullend radiotherapie. Tijdens de radiotherapie en de eerste maanden daarna kon zij slechts met moeite haar lichaamsgewicht op niveau houden omdat zij een droge mond en keel had gekregen door de radiotherapie. De radiotherapie had ook een beschadiging van de smaakbekers veroorzaakt. Op het moment dat haar smaak iets terugkeerde, ongeveer 6 maanden na beëindiging van de radiotherapie, wilde zij weer aardbeien eten. Dit draaide echter op een grote deceptie uit want de aardbeien smaakten in haar beleving naar 'aardolie'. De patiënt had weliswaar haar smaak deels teruggekregen, maar de smaakperceptie was sterk veranderd. 

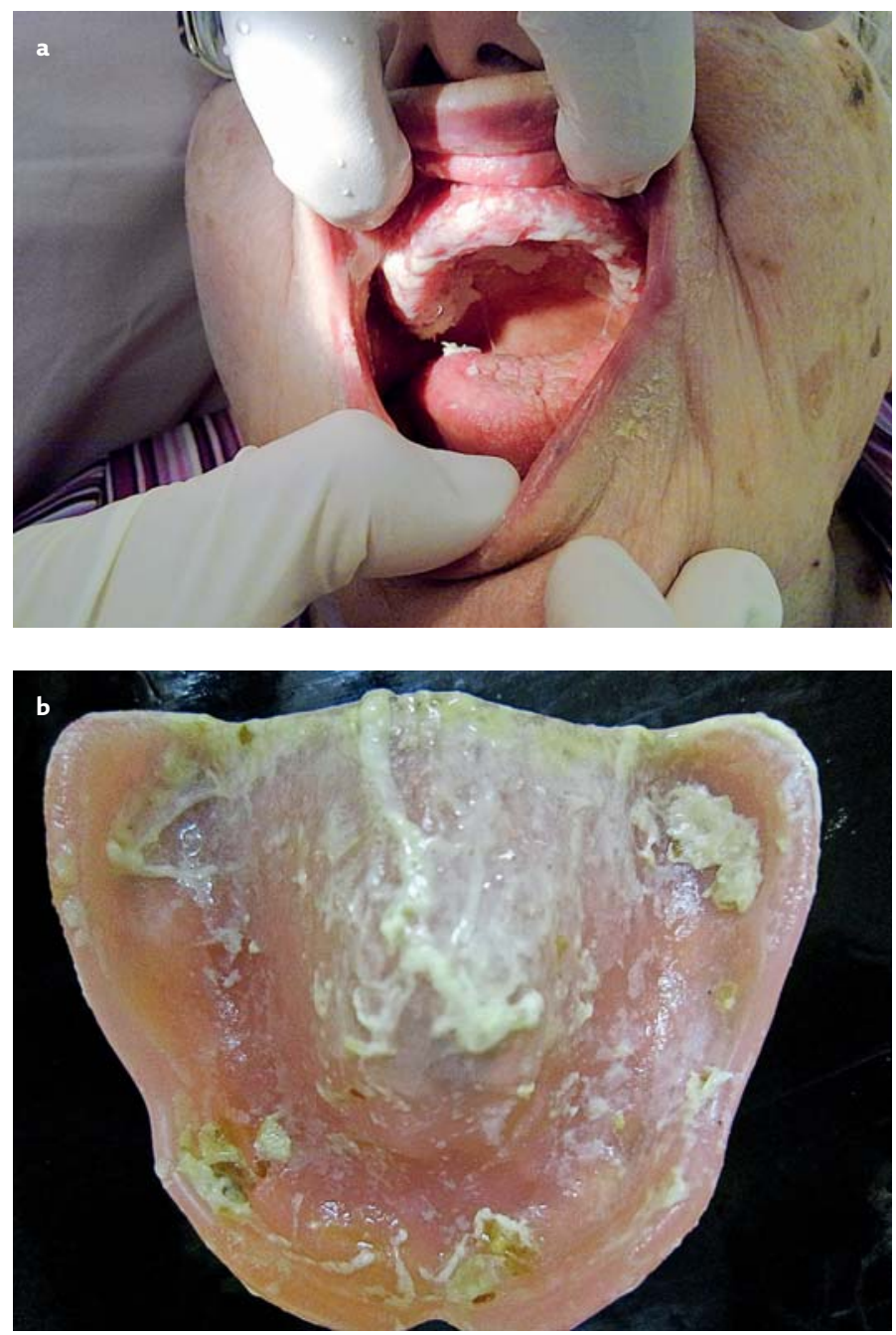

Afb. 1. Voedselresten op de tong en de orale mucosa (a) en op een gebitsprothese (b)

van kanker of de behandeling ervan, treedt gewichtsverlies op (Hutton et al, 2007; Jager-Wittenaar et al, 2007; Sánchez-Lara et al, 2010). Het is gebleken dat de mate waarin vetzuren worden geproefd samenhangt met de energie-inname (Stewart et al, 2010). Personen met een hypersensitiviteit voor vetzuren hebben niet alleen een lagere vet- en energie-inname, maar tevens een lagere lichaamsgewicht/ lichaamslengte-ratio ('body mass index') dan personen met een hyposensitiviteit voor vetzuren.

Chemosensorische stoornissen kunnen niet alleen leiden tot gewichtsverlies, maar ook tot gewichtstoename, vooral bij patiënten met anosmie, hyposmie of hypogeusie (Mattes et al, 1990; Mattes en Cowart, 1994). De gewichtstoename wordt veroorzaakt door het gebruik van extra suiker en een verhoogde voedselinname om het verminderde genot van voedingsmiddelen te compenseren. Voorts zijn er aanwijzingen dat vrouwen met obesitas umami intenser waarnemen dan vrouwen met overgewicht of een normaal gewicht (Donaldson et al, 2009). De rol van de smaakperceptie van umami bij het ontstaan van overgewicht is echter nog onduidelijk.

Naast veranderingen in het lichaamsgewicht kunnen patiënten met een smaak- en/of reukstoornis ook te weinig vitaminen en mineralen innemen. Patiënten met ernstige, langdurige dysgeusie, niet veroorzaakt door een maligniteit, liepen risico op een te lage inname van vitamine A, vitamine C, calcium en zink (Mattes-Kulig en Henkin, 1985).

\section{Behandeling}

Het uitgangspunt voor elke behandeling is uiteraard het afnemen van een zorgvuldige anamnese die de mogelijke oorzaken van een reuk- of smaakstoornis opspoort. De diagnostiek van reukstoornissen richt zich op endoscopisch onderzoek van de neus- en keelholte en psychosomatische reuktesten.

\section{Medicatie en/of chirurgische behandeling}

Een causale therapie is bij reukstoornissen vaak alleen voorhanden in geval van tekorten, bijvoorbeeld zinkgebrek bij hemodialysepatiënten (Hüttenbrink, 1995). Toediening van een zinkpreparaat, zoals zinkgluconaat (bijvoorbeeld 3 maal daags een tablet van $50 \mathrm{mg}$ ) of zinksulfaat (bijvoorbeeld 4 maal daags een tablet van $25 \mathrm{mg}$ ), zorgt in veel gevallen voor een verbetering (Hüttenbrink, 1995; Heckmann et al, 2005). Ook patiënten met smaakstoornissen gerelateerd aan een deficiëntie van gustine zijn vaak gebaat bij orale toediening van 4 maal daags $25 \mathrm{mg}$ zinksulfaat.

Reukverlies dat zich tijdelijk voordoet of geleidelijk ontstaat na een neusverkoudheid dient nader te worden onderzocht. Hierbij spelen meestal een slechte neuspassage en slijmvlieszwelling een rol. Een nauwe neusgang kan door een chronische ontsteking van de slijmvliezen, slijmproductie en veranderde samenstelling verder worden afgesloten en aanleiding geven tot afwijkingen van de sinus maxillaris (Loury en Kennedy, 1991). In tweede instantie kan dit invloed hebben op het reukepitheel. Bij deze aandoeningen moet worden gestreefd naar een adequate ontzwelling van de neusslijmvliezen door middel van medicatie of door een chirurgische behandeling (Scott et al, 1988; Hosemann et al, 1993). Beschadiging van het neusslijmvlies door virale, toxische of infectieuze agentia is vaak niet of slecht te behandelen.

Patiënten met een atopische constitutie en reukstoornissen moeten worden onderzocht op het voorkomen van chronische vormen van een allergische rinopathie en vergrote tonsillen. Ook deze patiënten kunnen vaak succesvol worden behandeld met lokale corticosteroïden en/of een chirurgische behandeling ter bevordering van de neuspassage (Ghorbanian et al, 1983).

Centrale en neuronale dysosmie reageren vaak goed op toediening van tricyclische antidepressiva, zoals imipramine (Hüttenbrink, 1995).

Smaak- en reukstoornissen die zijn gerelateerd aan medicamentgebruik zijn vaak te behandelen door het staken of veranderen van de medicatie (Ackerman en Kasbekar, 1997; Ship, 1999).

\section{Mondzorg}

In de mondzorg wordt een gestoorde smaakperceptie regelmatig gezien bij rokers, personen met een slechte parodontale conditie en personen met een slechte mondhygiëne. 


\section{Casus 4}

Een 56- jarige patiënt klaagde over een vieze smaak. De patiënt gaf aan dat deze smaak steeds rechts in de mond begon, maar kon niet precies aanduiden waar het vandaan kwam. Bij klinisch onderzoek bleek de mondhygiëne goed en bij sonderen van de gingiva werd hier en daar een lichte bloedingsneiging, maar geen parodontale of peri-implantaire pocket gevonden (afb. a), noch waren er aanwijzingen voor fistels. Voor de zekerheid werd een panoramische röntgenopname gemaakt. Daarop was te zien dat in de regio 46 een zeer kort implantaat aanwezig was met veel peri-implantair botverlies (afb. b). Besloten werd het implantaat te verwijderen waarna de klachten verdwenen (afb. c).

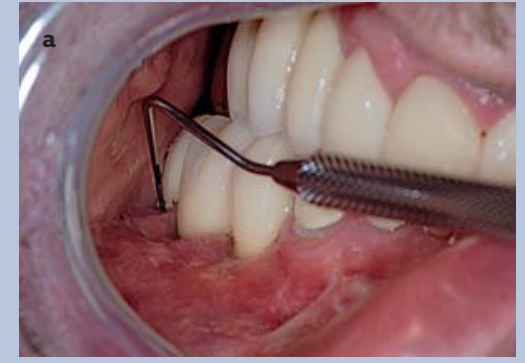

a. Bij voorzichtig sonderen werd geen pocket gevonden noch bloeding gezien.

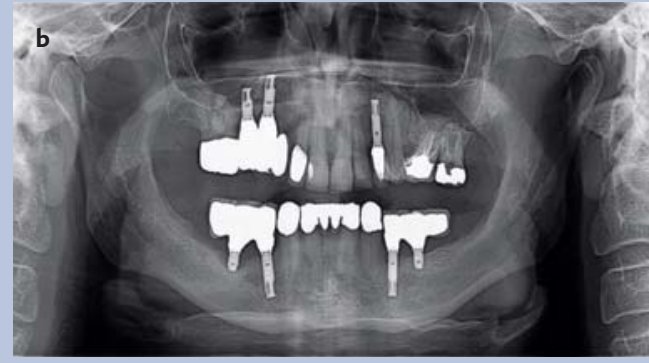

b. Panoramische röntgenopname met in de regio 46 een zeer kort implantaat met veel verlies van peri-implantair bot.

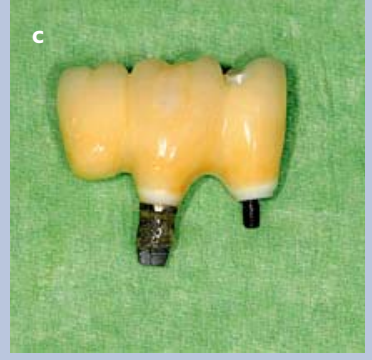

c. Door het losdraaien van de schroef van de implantaatopbouw op positie 45 kwam het implantaat mee met de suprastructuur.
De verhoogde concentratie aan zwavelverbindingen draagt hieraan bij. Staken van roken, optimaliseren van de parodontale conditie en het instellen van een goede mondhygiene zijn hiervoor de eerst aangewezen behandeling.

Orale halitose en dysgeusie worden vaak aangetroffen bij patiënten met hyposialie. Vooral bij zorgafhankelijke ouderen, zoals verpleeghuisbewoners, is het niet ongebruikelijk veel aanslag en/of voedselresten op de orale mucosa en een eventuele gebitsprothese te zien (afb. 1).

Een groter diagnostisch probleem vormen de patiënten die klagen over een lokale dysgeusie die lijkt te zijn gerelateerd aan de gebitselementen zonder dat hiervoor een oorzaak zoals cariës of een parodontale aandoening is aan te wijzen (casus 4). Veelal betreft dit patiënten bij wie recent een restauratie met plastische materialen of een kroon of brug is vervaardigd. Om te beoordelen of de stoornis hiermee samenhangt, kan het vervaardigen van een gebitsbeschermer zinvol zijn (afb. 2). Dit heeft uiteraard alleen zin als de aangebrachte restauraties technisch goed zijn en geen cariës of ontstekingsbronnen zijn gevonden. Ook moet eerst worden uitgezocht of van vervanging van de restauratie een positief effect kan worden verwacht, want de toepassing van verschillende metaalsoorten in elkaars omgeving kan aanleiding geven tot galvanische problemen. Als bij het dragen van een gebitsbeschermer de dysgeusie (tijdelijk) verdwijnt, kan men door het selectief inkorten en dragen van deze gebitsbeschermer het oorzakelijke gerestaureerde gebitselement of de oorzakelijke regio op het spoor komen. Ook kan met een gebitsbeschermer worden beoordeeld of de klacht wel door een restauratie wordt veroorzaakt. Vaak blijk dit namelijk niet het geval te zijn.

\section{Reukrevalidatie}

Patiënten die om oncologische redenen een laryngectomie hebben ondergaan, worden geconfronteerd met drastische fysiologische veranderingen van hun normale laryngeale
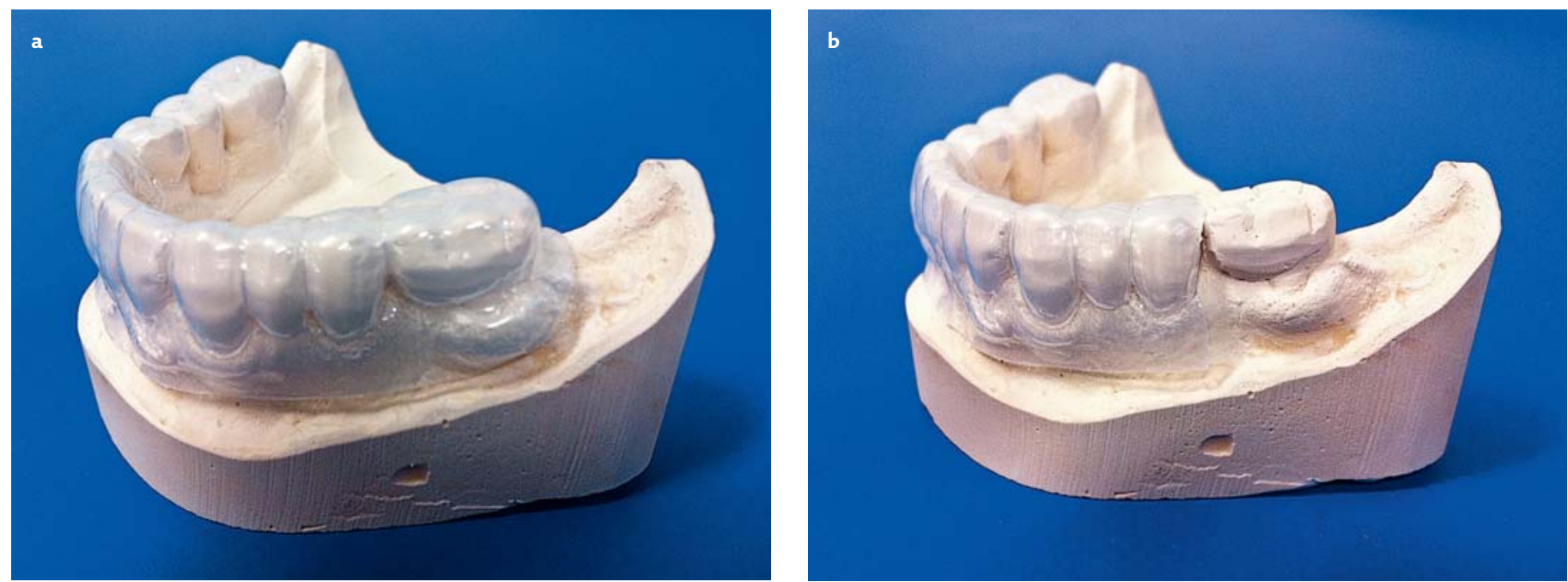

Afb. 2. Gebitsmodel met daarop een gebitsbeschermer (a). Ingekorte gebitsbeschermer om de regio te bepalen waar mogelijk de bron van de dysgeusie zich bevindt (b). 
spraak, het slikproces en de ademhaling (Timmermans et al, 2012). De ademhaling via een tracheostoma heeft consequenties voor de normale nasale conditionering van de ingeademde lucht en voor de reukperceptie omdat de ademhaling niet meer via de neus verloopt. Met de tijd heeft het ontbreken van luchtstroom door de neus ook gevolgen voor het neusslijmvlies dat geleidelijk kan gaan zwellen met kans op verhoogde slijmvorming. Dit wordt een aspecifieke rinopathie genoemd. Hierdoor kan de nog resterende reukperceptie verder afnemen. Dit heeft geleid tot de ontwikkeling van specifieke technieken die sommige patiënten zelfs spontaan aanwenden om met behulp van faryngeale en palatinale bewegingen een anterograde of retrograde luchtstroom door de neus te realiseren (Van Dam et al, 1999). Inmiddels is gebleken dat deze functionele vorm van anosmie door langdurig afwezige prikkeling of stimulatie van het reukepitheel voor geurprikkels in de nasale luchtstroom niet leidt tot een definitieve anosmie door atrofie van de nervus en/of bulbus olfactorius (Welge-Luessen et al, 2000). De diverse reukrevalidatiemethoden dienen in het totale revalidatieprogramma voor patiënten die een laryngectomie hebben ondergaan te worden opgenomen.

\section{Overige}

Bij smaak- en reukstoornissen is begeleiding door een diëtist zinvol voor zowel praktische voedingsadviezen om het eten aantrekkelijker te maken als voor het verbeteren of handhaven van de voedingstoestand. Verder kan, zeker bij patiënten met permanente smaak- en reukstoornissen, worden overwogen aanvullende psychologische en/of maatschappelijke ondersteuning aan te bieden bij het verwerken en aanvaarden van het reuk- en smaakverlies. Deze aspecten worden in het volgende artikel van deze serie belicht.

\section{Literatuur}

* Ackerman BH, Kasbekar N. Disturbances of taste and smell induced by drugs. Pharmacotherapy 1997: 17: 482-496

* Battaglia A. Sensory impairment in mental retardation: a potential role for NGF. Arch Ital Biol 2011; 149: 193-203.

* Comeau TB, Epstein JB, Migas C. Taste and smell dysfunction in patients receiving chemotherapy: a review of current knowledge. Support Care Cancer 2001: 9: 575-580.

* Dahlslett SB, Goektas O, Schmidt F, Harms L, Olze H, Fleiner F. Psychophysiological and electrophysiological testing of olfactory and gustatory function in patients with multiple sclerosis. Eur Arch Otorhinolaryngol 2012; 269: 1163-1169.

* Dam FSAM van, Hilgers FJM, Emsbroek G. Deterioration of olfaction and gustation as a consequence of total laryngectomy. Laryngoscope 1999; 109: 1150-1155.

* Donaldson LF, Bennett L, Baic S, Melichar JK. Taste and weight: is there a link? Am J Clin Nutr 2009; 90 (Suppl.): 800S-803S

* Ghorbanian SN, Paradise JL, Doty RL. Odor perception in children in relation to nasal obstruction. Pediatrics 1983; 72: 510-516

* Heckmann SM, Hujoel P, Habiger S, et al. Zinc gluconate in the treatment of dysgeusia - a randomized clinical trial. J Dent Res 2005; 84: 35-38.
* Helms JA, Della-Fera MA, Mott AE, Frank ME. Effects of chlorhexidine on human taste perception. Arch Oral Biol 1995; 40: 913-920.

* Hong JH, Ömür-Özbek P, Stanek BT, et al. Taste and odor abnormalities in cancer patients. J Support Oncol 2009; 7: 58-65.

* Hosemann W, Goertzen W, Wohlleben R. Olfaction after endoscopic endonasal ethmoidectomy. Am J Rhinol 1993; 7: 11-15.

* Hovan AJ, Williams PM, Stevenson-Moore P, et al. A systematic review of dysgeusia induced by cancer therapies. Support Care Cancer 2010; 18: 1081-1087.

* Hüttenbrink KB. Störungen des Riech- und Schmecksinns. Ther Umsch 1995; 52: 732-737.

* Hutton JL, Baracos VI, Wismer WV. Chemosensory dysfunction is a primary factor in the evolution of declining nutritional status and quality of life in patients with advanced cancer. J Pain Symptom Manage 2007; 33: 156-165.

* Jager-Wittenaar H, Dijkstra PU, Vissink A, Laan BF van der, Oort RP van, Roodenburg JL. Critical weight loss in head and neck cancer-prevalence and risk factors at diagnosis: an explorative study. Support Care Cancer 2007; 15: 1045-1050.

* Konstantinidis I, Chatziavramidis A, Printza A, Metaxas S, Constantinidis $J$. Effects of smoking on taste: assessment with contact endoscopy and taste strips. Laryngoscope 2010; 120: 1958-1963.

* Loury MC, Kennedy DW. Chronic sinusitis and nasal polyposis. In: Getchell TV, Bartoshuk LM, Doty RL, Snow J (eds.). Smell and taste in health and disease. New York: Raven Press, 1991.

* Matson A, Wright M, Oliver A, et al. Zinc supplementation at conventional doses does not improve the disturbance of taste perception in hemodialysis patients. J Ren Nutr 2003; 13: 224-228.

* Mattes RD, Cowart BJ, Schiavo MA, et al. Dietary evaluation of patients with smell and/or taste disorders. Am J Clin Nutr 1990; 51: 233-240

* Mattes RD, Cowart BJ. Dietary assessment of patients with chemosensory disorders. J Am Diet Assoc 1994; 94: 50-56.

* Mattes-Kulig DA, Henkin RI. Energy and nutrient consumption of patients with dysgeusia. J Am Diet Assoc 1985; 85: 822-826.

* Mauersberger H, Witte PU. Disappearance of captopril-induced taste disturbance after substitution with angiotensin-converting-enzyme inhibitor HOE 498. Lancet 1985; 1 (8427): 517-518.

* Mott AE, Leopold DA. Disorder in taste and smell. Med Clin North Am 1991; 75: 1321-1353.

* Nieuw Amerongen A van, Veerman ECI, Vissink A. Speeksel, speekselklieren en mondgezondheid. Houten: Bohn Stafleu van Loghum, 2008.

* Reuber M, Al-Din AS, Baborie A, Chakrabarty A. New variant Creutzfeldt-Jakob disease presenting with loss of taste and smell. J Neurol Neurosurg Psychiatry 2001; 71: 412-413.

* Ritchie CS. Oral health, taste, and olfaction. Clin Geriatr Med 2002; 18: 709-717.

* Ripamonti C, Zecca E, Brunelli C, et al. A randomized, controlled clinical trial to evaluate the effects of zinc sulfate on cancer patients with taste alteration caused by head and neck irradiation. Cancer 1998; 82: $1938-1945$

* Ruo Redda MG, Allis $S$. Radiotherapy-induced taste impairment. Cancer Treat Rev 2006; 32: 541- 547.

* Sánchez-Lara K, Sosa-Sánchez R, Green-Renner D, et al. Influence of taste disorders on dietary behaviors in cancer patients under chemotherapy. Nutr J 2010; 24: 9-15.

* Scott A, Cain WS, Clavet G. Topical corticosteroids can alleviate olfac- 
tory dysfunction. Chem Senses 1988; 13: 735.

* Ship JA, Weiffenbach JM. Age, gender, medical treatment, and medication effects on smell identification. J Gerontol 1993; 48: M26-M32.

* Ship JA. The influence of aging on oral health and consequences for taste and smell. Physiol Behav 1999; 66: 209-215.

* Spielman AI. Chemosensory function and dysfunction. Crit Rev Oral Biol Med 1998; 9: 267-291.

* Stewart JE, Feinle-Bisset C, Golding M, Delahunty C, Clifton PM, Keast $R S$. Oral sensitivity to fatty acids, food consumption and BMI in human subjects. Br J Nutr 2010; 104: 145-152.

* Swart EL, Waal I van der, Wilhelm AJ. Orale bijwerkingen van geneesmiddelen. Gebu 2001; 35: 133-137.

* Tan BH, Fearon KC. Cachexia: prevalence and impact in medicine. Curr Opin Clin Nutr Metab Care 2008; 11: 400-407.

* Timmermans AJ, Krap M, Hilgers FJM, Brekel MWM van den. Spraakrevalidatie na een totale laryngectomie. Ned Tijdschr Tandheelkd 2012; 119: 357-361.

* Vissink A, Nieuw Amerongen A van, Oremus EThHGJ. De invloed van geneesmiddelen op het orofaciale gebied. Ned Tijdschr Tandheelkd 1999; 106: 254-263.

* Vissink A, Weissenbruch $R$ van, Nieuw Amerongen A van. Smaak- en reukstoornissen. Ned Tijdschr Tandheelkd 2001; 108: 229-236.

* Vissink A, Jager-Wittenaar H, Visser A, Spijkervet FKL, Weissenbruch $R$ van, Nieuw Amerongen A van. Oral medicine 3. Anatomie, fysiologie en diagnostische overwegingen bij smaak- en reukstoornissen. Ned Tijdschr Tandheelkd 2013; 120: 34-39.

* Welge-Luessen A, Kobal G, Wolfensberger M. Assessing olfactory function in laryngectomees using the Sniffin'Sticks test battery and chemosensory evoked potentials. Laryngoscope 2000; 110: 303-306.
Summary

Oral medicine 4. Clinical aspects and treatment of taste and smell disorders

Taste and smell perception are closely related. Many chemosensory disorders which result in faulty taste are in fact smell disorders. Causes of chemosensory disorders which call for attention are ageing, medication, natural proteins, burning mouth syndrome, nerve injuries, aerate disorders in the neighbourhood of the sense of smell, damage to the smell epithelium, and oncologic diseases or their treatment. A chemosensory disorder has implications for food delight and psychological well-being, may lead to weight loss or increase and to deficient intake of vitamins and minerals. A chemosensory disorder can be treated by medication, surgical intervention, improvement of oral health, smell rehabilitation, and dietary advice.

\section{Bron}

A.Vissink ${ }^{1}$, H. Jager-Wittenaar ${ }^{1}$, A. Visser ${ }^{1}$, F.K.L. Spijkervet ${ }^{1}$, R. van Weissenbruch $^{2}$, A. van Nieuw Amerongen ${ }^{3}$

Uit ${ }^{1}$ de afdeling Mondziekten, Kaak- en Aangezichtschirurgie van het Universitair Medisch Centrum Groningen, ${ }^{2}$ de afdeling Keel-, Neus- en Oorheelkunde van het Wilhelmina Ziekenhuis Assen en ${ }^{3}$ de afdeling Conserverende en Preventieve Tandheelkunde van het Academisch Centrum Tandheelkunde Amsterdam (ACTA)

Datum van acceptatie: 3 oktober 2012

Adres: prof. dr. A. Vissink, UMCG, postbus 30.001, 9700 RB Groningen a.vissink@kchir.umcg.nl

\section{Verantwoording}

Dit artikel is een actualisering van een eerder in dit tijdschrift gepubliceerd artikel (Vissink et al, 2001). 